\title{
Municipal support of wireless access network rollout: a Game Theoretic Approach
}

Mathieu Tahon $^{\mathrm{a}, *}$, Bart Lannoo ${ }^{\mathrm{a}}$, Jan Van Ooteghem ${ }^{\mathrm{a}}$, Koen Casier ${ }^{\mathrm{a}}$, Sofie Verbrugge ${ }^{\mathrm{a}}$, Didier

Colle $^{\mathrm{a}}$, Mario Pickavet ${ }^{\mathrm{a}}$, Piet Demeester ${ }^{\mathrm{a}}$

${ }^{\text {a }}$ Ghent University-IBBT

Gaston Crommenlaan 8, bus 201

B-9050 Gent, Belgium

\{Mathieu.Tahon; Bart.Lannoo; Jan.VanOoteghem; Koen.Casier; Sofie.Verbrugge; Didier.Colle;

Mario.Pickavet; Piet.Demeester\}@intec.ugent.be

*Corresponding author:

Mathieu.Tahon@intec.ugent.be

Ghent University-IBBT

Gaston Crommenlaan 8, bus 201

B-9050 Gent, Belgium

Tel: +32 93314977

Fax: +3293314899 
Abstract:

Next generation access networks are expected to bring ubiquitous broadband access and have attracted interest of municipal governments. This paper investigates the support by municipal authorities for the rollout of such a city-wide wireless broadband access network. Different business cases for 3G and WiFi operators are developed and it is indicated how to model the specificities for commercial versus public players. Furthermore, a game theoretic approach is used to investigate the investment options of the municipal player. It is shown that a partnership between a commercial and public player is the most likely investment strategy. However, bringing more players into the competitive environment reduces the intention of the commercial partner to engage in the public private partnership (PPP).

Keywords: game theory, techno-economics, municipal network, wireless access network, 3G, WiFi 


\section{Introduction}

The demand for broadband access keeps growing worldwide. In 2009, over 466 million people were using broadband Internet services, and this number will keep growing in the following years. Together with broadband access, mobility is gaining importance. In 2009, there were 4.7 billion mobile telephone subscriptions worldwide (ITU, 2009). Resulting from these two needs, mobile broadband access is an important issue for operators. However, recent numbers on mobile broadband usage show a low uptake, with only 8.5 million users worldwide by the end of 2009. Nevertheless, with growth figures averaging around 5\% per quarter (Point Topic, 2010), there is significant business potential in this market.

The introduction of these next generation access networks (NGANs) is expected to bring a broad range of indirect revenues. Efficiency gains, attracting new businesses and the resulting raise in employment are only a few examples. These are the main drivers for public authorities to invest in the rollout of NGANs.

In this paper focus is on the rollout of a mobile broadband access network. Technoeconomic papers studying the viability of WiFi and WiMAX networks have already been conducted in Smura (2006), Sadowski, Verheijen, and Nucciarelli (2008) and Van Ooteghem et al. (2009). General conclusion is that a deployment can be profitable, if the right technology, rollout zone and strategy are chosen.

The standard economic evaluation methods evaluate projects from a monopolistic point of view. However, operators do not act in a monopolistic market, and competition between different operators is fierce. Game Theory (GT) offers methods to bring competition into the business models. An overview of the use of GT in the telecommunication research area can be found in Altman, Boulogne, El-Azouzi, Jiménez, and Wynter (2006). However, the different topics described focus on non- 
economic games. Extensive economic games covering a fixed network rollout have been described in Casier, Lannoo, Van Ooteghem, Verbrugge, Colle, Pickavet, and Demeester (2009).

This paper will apply game theoretic concepts to perform an extended economic analysis of a wireless network rollout. In Lannoo et al. (2009), a municipal WiFi player and a $3 \mathrm{G}$ mobile virtual network operator (MVNO) were already brought into competition.

Several research questions still need to be addressed in this topic. This paper extends the research of Lannoo et al. (2009) with the following questions. Will the municipality be interested in a public private partnership (PPP) with a commercial WiFi provider in the first place? Or will it rollout its own network, thereby avoiding any problems with hidden subsidization of a private project and competition distortion? On what grounds will this interest be based?

To answer these questions, the methodology proposed by Verbrugge, Casier, Van Ooteghem, and Lannoo (2009) was followed. After sketching the setting of the business case in Section 2, the business cases for the two considered access technologies, WiFi and 3G, is developed in Section 3 and 4. The business model for the WiFi player of Lannoo, et al. (2009) is adapted to capture the impact of a municipality on the cost and revenue structure. While private players focus on value creation for shareholders, and typically use the Net Present Value (NPV) concept to capture this value creation, a public player is interested in public welfare gain. To cover this value, the indirect revenues concept is introduced.

After describing the basic concepts of GT in Section 5, Section 6 and 7 perform the actual game theoretic analysis. First, focus is on the strategic choice of the municipality. The municipality can choose to enable a commercial player to rollout a wireless NGAN via a PPP. Or it can also choose to act alone, as a full commercial 
player. Using a game theoretic approach, the best strategy for the municipal player is identified. In Section 7, extra players are brought into the competitive environment, to control the viability of the PPP under realistic assumptions. The numerical models used for the business modeling allow tackling this complex problem. Finally, Section 8 provides conclusions and recommendations.

\section{Case setting: Providing wireless broadband access in a municipal setting}

To investigate the different partnership and competition scenarios for the introduction of city-wide wireless access networks, a general model has been developed. The business cases derived from this model will focus on a rollout in the city of Ghent. Ghent is the third largest city in Belgium, with over 240000 inhabitants. Ghent also houses 50000 students and attracts almost 400000 tourists per year. The rollout area considered in this paper was identified as the most interesting in Van Ooteghem et al. (2009) and covers $14 \mathrm{~km}^{2}$. Before going into detail on the business cases of the different players, an overview of important factors influencing these cases is given. User adoption is necessary to estimate the future revenues, the technology of the different players serves as input factor for the network modeling, and other general economic parameters are used to evaluate the business case. The regulatory aspect will also be discussed, since for projects with public support, competition regulation is an important aspect, and will as such influence the business cases.

\subsection{User adoption}

User adoption is often the basis of the economic calculations since users are the main revenue driver. In a competitive setting, the number of customers is not fixed per 
player. The total adoption is considered to be given by a general adoption model and split the adoption per player.

The Gompertz model is chosen to estimate the user adoption of Mobile Internet through the years. According to Cardenas, Garcia-Molina, Sales, and Capmany (2004), this adoption model gives the best fit in case of a telecom business case compared to other models. The mathematical formula (1) has three parameters to change: its inflection point $(a)$, slope $(b)$ and size $(m)$. The parameters used in this case are shown in Table 1 and visualized in Fig. 1. Recent research into the penetration rate of wireless broadband showed an average penetration rate around 16\% (De Marez, Evens, \& Stragier, 2011). The adoption model used in this paper shows an adoption around 17\% in 2011.

$$
S(t)=m * e^{-e^{-b(t-a)}}
$$

In this case, the market is divided in four different segments, since the adoption of the service will differ between them.

Table 1: Adoption parameters for the different market segments (Van Ooteghem et al., 2009)

\begin{tabular}{|l|l|l|l|}
\hline User type & a & b & $\mathbf{m}$ \\
\hline Inhabitants & 2011.5 & 0.64 & $20.00 \%$ \\
\hline Students & 2011.5 & 0.64 & $33.33 \%$ \\
\hline Tourists & 2011.5 & 0.64 & $5.00 \%$ \\
\hline Industry & 2011.5 & 0.64 & $5.00 \%$ \\
\hline
\end{tabular}




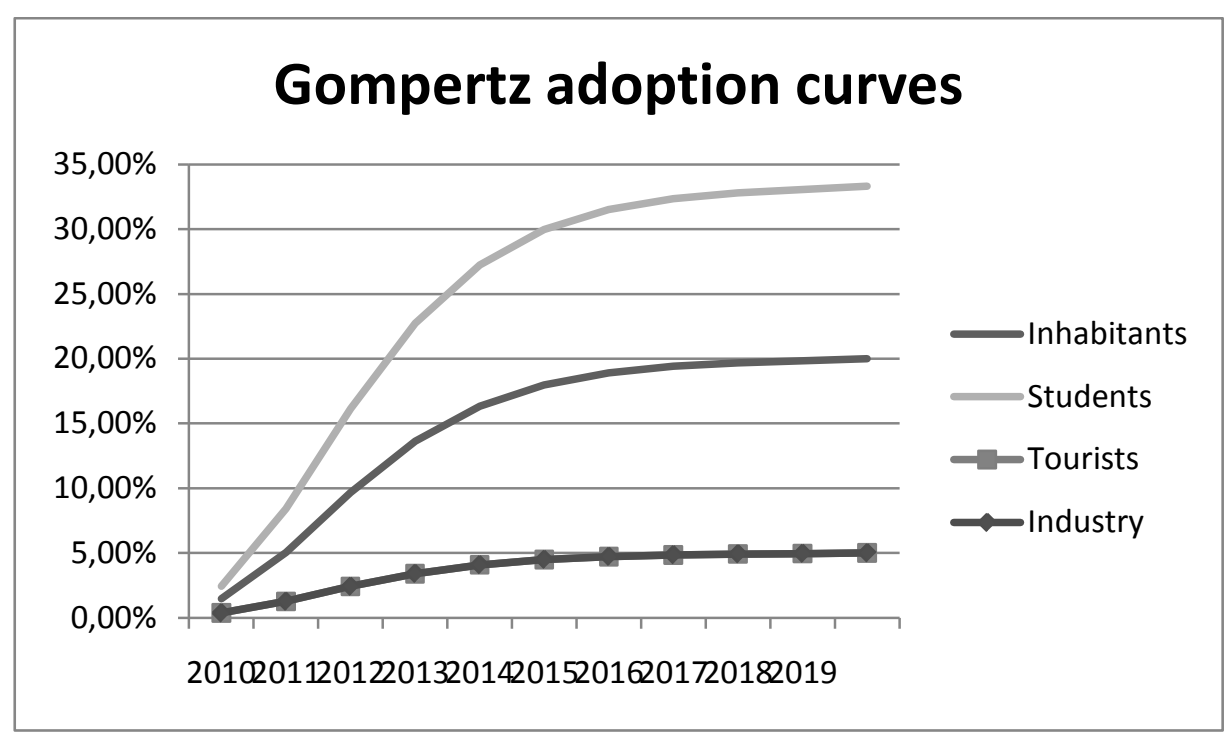

Fig. 1: Adoption curves ${ }^{\mathrm{A}}$

A Tourists and Industry adoption overlap

\subsection{Business players}

The model introduced in this paper studies the introduction of several wireless access networks. In order to avoid excessive complexity, the different possible technologies to offer the service have been reduced to WiFi and 3G or their successors. Previous research (Van Ooteghem et al., 2009) already showed that in small, densely populated areas, WiFi technology is commercially interesting. This paper will focus on the strategic choice by the municipality, in a setting with two WiFi players and one 3G player. The two WiFi players represent the municipality and a commercial partner respectively, while the $3 G$ player is an established mobile network operator (MNO), directly competing with the WiFi providers.

\subsection{Business case evaluation parameters}

To evaluate the business cases, a standard NPV analysis is carried out, by calculating the yearly discounted cash flows for every player. For technological projects, a discount factor between $10 \%$ and $15 \%$ is common (Verbrugge et al., 2009). The Capital Asset 
Pricing Model links return with risk, stating that investments bearing a higher risk require a higher return on investment (ROI) (Sharpe, 1963). The combination of a risky technological investment and low initial capital expenditures made us choose for an average required ROI of $12 \%$. The considered projects are evaluated over the period 2010-2019.

The exact cost of the initial investments made for a physical network deployment and supporting services are very operator specific, and therefore approximations come with a degree of uncertainty. To handle these uncertainties, the model is built in a generic way, allowing easy modifications of input parameters.

\subsection{Regulation}

Regulation is an important aspect in the telecommunication sector. One main issue is directly related to this research topic: Competition regulation enforced by European and national governments. The most known example is the questioning of the city of Amsterdam by the European Commission (EC). Together with private investors, the municipal government financed the rollout of a large-scale fiber network. After complaints by other commercial players, the EC investigated if the city’s investment was compatible with state aid rules. From this case, it can be concluded that the municipality must participate in the project just like a private investor (the market economy investor principle) (RAPID, 2006).

\section{Viability of WiFi deployment}

This section describes the stand-alone business case for a WiFi player. After a brief overview of the used technology, an investment analysis is derived from the cost and revenue modeling. 


\subsection{Technical info}

WiFi (Wireless Fidelity) is a certification label for wireless local area network (WLAN) devices that comply with the international IEEE 802.11 standards and sub-standards. Those labels are distributed by the WiFi Alliance, and interoperability between different products is ensured. Different flavors of the IEEE 802.11 standard exist, where 802.11a, 802.11b, 802.11g and 802.11n are presently the most wide spread variants. WiFi devices were primarily intended to be installed and managed by the customer. However, some telecom operators are nowadays exploiting WiFi access points (APs) at public places to offer their clients a fast wireless Internet connection, as an extension to their main telecom services.

In this paper, the recent 802.11n standard (released in October 2009) is used, because of the higher throughput, compared to the older standards. The $802.11 \mathrm{n}$ standard can be considered as the successor of 802.11g and it is backwards compatible with the latter. Two non-licensed radio frequency bands are defined for WiFi, i.e. 2.4 and $5 \mathrm{GHz}$, and there is opted for a $20 \mathrm{MHz}$ channel bandwidth. The wireless municipality network is expected to work within the $2.4 \mathrm{GHz}$ frequency band, for which three low-interfering $20 \mathrm{MHz}$ channels are available. A maximum achievable PHY data rate of $65 \mathrm{Mbps}$ per $20 \mathrm{MHz}$-channel can be attained. The 802.11n standard also supports multiple antenna techniques like Multiple-Input Multiple-Output (MIMO), which can extend either the data rate or the range of the WiFi signals. For outdoor APs, MIMO is better used to extend the wireless range while keeping a $65 \mathrm{Mbps}$ channel, than to increase the data rate.

\subsection{Techno-economic model}

The used techno-economic model for WiFi is based on the model described in Van Ooteghem et al. (2009). Van Ooteghem et al. (2009) introduced a full economic 
feasibility analysis of the rollout of a wireless access network in the city of Ghent. In this section, a summary of that model is provided and the main differences with the model used in this paper are indicated.

\subsubsection{Deployment model}

An import aspect of developing a full techno-economic model of a wireless access network is the calculation of the number of WiFi APs that need to be deployed in order to assure both coverage and sufficient available bandwidth to serve all users. Four import input factors to assess the needed number of APs can be distilled: covered area, number of users, required bandwidth and physical parameters of the technology. The physical parameters define the signal power, gains, losses, receiver sensitivity and margins (fade, shadow, interference ...) for calculating the maximum range of the technology at a given data rate. Together with the three other input factors, the amount of needed APs can be defined.

In Van Ooteghem et al. (2009) six different technical scenarios for deploying a wireless access network were proposed. Within these six technical scenarios, two main access technologies were considered: WiFi and WiMAX. The backhaul solutions were varied as follows: all APs individually connected to a fixed backhaul network (e.g. digital subscriber line (DSL) or fiber); meshed networks of a single wireless technology, reducing the number of fixed backhaul connections; or a combination between WiFi (as access) and WiMAX (as wireless backhaul) technology. The best choice found from a techno-economic point of view was a meshed WiFi network. The main deployment details can be found in Table 2 .

Table 2: WiFi deployment scenario

\begin{tabular}{|l|l|l|}
\hline $\begin{array}{l}\text { Wireless } \\
\text { connection }\end{array}$ & Technology & $\begin{array}{l}\text { Antenna heights } \\
(\mathrm{m})\end{array}$ \\
\hline
\end{tabular}




\begin{tabular}{|l|l|l|}
\hline $\begin{array}{l}\text { AP to user } \\
\text { Backhaul }\end{array}$ & WiFi & 6 to 1.5 \\
6 to 6
\end{tabular}

\subsubsection{Costs}

Costs are typically divided in two subsections. Upfront investment costs in fixed assets are called Capital Expenditures (CapEx), while recurring costs like maintenance and personnel costs are Operational Expenditures (OpEx).

\section{Capital Expenditures}

The deployment of a wireless access network requires a large upfront investment. Both WiFi APs and the wireless backhauling need to be installed. The APs will be subject to failure, caused by external factors like weather conditions and vandalism, so a replacement investment is assumed every five years. Next to the APs, an investment in central infrastructure is also necessary. This can be subdivided in core equipment, such as routers and servers, and general Network Operating Centre (NOC) infrastructure like power supplies and cooling. All costs are based on Van Ooteghem et al. (2009), but prices are set at the 2010 price level.

\section{Operational Expenditures}

WiFi APs are deployed on either public or private sites. Site rental will thus be a major aspect of the yearly OpEx. Access to public sites is typically cheaper than access to private sites. This is modeled by halving the cost for site rental when it concerns a public site. The reduction of administrative overhead and the cheaper access to sites as the major advantages of a municipal partner were already mentioned. This comes forward in the model in the proportion of public sites. In absence of a public player in the project, only $10 \%$ of all sites are assumed to be public. When a municipality steps into the partnership, this rate shifts completely, with $90 \%$ public sites. These numbers 
are based on discussions with operators. The dimensioning provides the number of necessary sites.

The backhauling APs will be connected to a fixed backhaul connection. A volumedependent connection price per connected AP per year is included.

Operations, administration and maintenance (OA\&M) are mainly driven by the number of APs and their equipment. Personnel costs for planning and maintenance of the APs are included (Vacature, 2010).

The cost for Customer Relationship Management (CRM) is fully driven by the number of customers. Offering a new service raises for example the need for a helpdesk department. Lannoo, Verbrugge, Van Ooteghem, Quinart, Colle, Pickavet, and Demeester (2007) proposed a method to calculate the helpdesk cost. Cost of sales, marketing and advertising complete the CRM cost and are based on Van Ooteghem et al. (2009).

\subsubsection{Revenues}

Revenues fall apart in two categories. There are the direct revenues, driven by the number of customers. For indirect revenues, the link between the revenues and the main activity, here the sale of wireless access, is indirect. It is however the existence of indirect revenues that makes network infrastructure projects so important for public players.

\section{Direct revenues}

Direct revenues can be derived from the forecasted number of customers. A distinction between different service offers is made, based on Van Ooteghem et al. (2009). Table 3 gives an overview of the monthly revenue per user for the different service categories for the considered network. The monthly revenues are based on prices for similar services offered by two commercial players in Belgium: namely the WiFi operator 
ZapFi and the WiMAX operator Clearwire. ZapFi will offer a WiFi service with prices starting from $€ 10$ per month in a nearby city (ZapFi, 2010), while Clearwire currently offers WiMAX subscriptions ranging between $€ 30$ for $1 \mathrm{Mbps}$ and $€ 45$ for $3 \mathrm{Mbps}$ per month (Clearwire website). The prices used in this paper are thus a reasonable compromise between these two different offers. To be able to offer a free service, other parties can buy advertising space which will be displayed to customers using the free subscription possibilities.

In Section 2.3, four different customer classes were described. Each class will have a different interest in each of the service offerings, as shown in Table 4. Inhabitants will be interested in using the free service, in addition to their existing fixed broadband connection. Students on the other hand will use the two monthly subscription possibilities as primary connection. The better bandwidth offer of these services will be more in line with their interests than the free service that only offers $512 \mathrm{kbps}$. Tourists and business users will mainly buy vouchers. While tourists are only interested in the vouchers and the free service, business users can, depending on their usage time, choose for a monthly subscription.

Table 3: Monthly revenue per WiFi service

\begin{tabular}{|l|l|l|l|}
\hline \multirow{2}{*}{ Service } & \multirow{2}{*}{$\begin{array}{l}\text { Subscription fee } \\
\text { (incl. VAT) }\end{array}$} & \multicolumn{2}{|l|}{ Offered Bandwidth } \\
\cline { 3 - 4 } & $€ 5$ (advertising) & Downstream & Upstream \\
\hline Free & $€ 12$ & $1 \mathrm{kbps}$ & $128 \mathrm{kbps}$ \\
\hline Low-bandwidth & $€ 20$ & $3 \mathrm{Mbps}$ & $256 \mathrm{kbps}$ \\
\hline High-bandwidth & $€ 12 \mathrm{kbps}$ \\
\hline Vouchers (per card) & $€ 9$ & $1 \mathrm{Mbps}$ & $256 \mathrm{kbps}$ \\
\hline
\end{tabular}

Table 4: Customer class and interest in WiFi services

\begin{tabular}{|l|l|l|l|l|}
\hline Service & Inhabitants & Students & Tourists & Business \\
\hline Free & $60 \%$ & $5 \%$ & $20 \%$ & $10 \%$ \\
\hline Low- & $25 \%$ & $60 \%$ & $0 \%$ & $10 \%$ \\
\hline
\end{tabular}




\begin{tabular}{|l|l|l|l|l|}
\hline bandwidth & & & & \\
\hline $\begin{array}{l}\text { High- } \\
\text { bandwidth }\end{array}$ & $15 \%$ & $35 \%$ & $0 \%$ & $20 \%$ \\
\hline Vouchers & $0 \%$ & $0 \%$ & $80 \%$ & $60 \%$ \\
\hline
\end{tabular}

\section{Indirect revenues}

It was already pointed out that indirect revenues form a major driver for public authorities to invest in NGANs. Indirect revenues are additional advantages caused by the main activity. Efficiency gains in public services are one of the drivers for indirect revenues. The wireless network helps the municipality in promoting several eServices. Next to these gains, this project can attract new businesses, extra employment and tax revenues. Due to the broad spectrum of possible indirect advantages, it is hard to estimate the total indirect revenues a project generates. A distinction is made between four different drivers to evaluate the indirect revenues, namely fixed, customer, service and investment.

Fixed indirect revenues have no specific driver, but setting up a wireless platform allows deploying new applications, which can lead to efficiency gains and cost reductions. Customers drive the second part of indirect revenues, as the impact of for example an eGovernment application or social network is assessed by the amount of users. A third part is service based: an increased wireless coverage and bandwidth might benefit several new applications like e-health and video services. The last component of indirect revenues is investment driven. The municipality can expect to attract companies and high educated inhabitants due to such an investment. A part of the invested money will flow back in the regional economy, and taxation will generate a money flow to the local government. The calculation of the indirect revenues is based on Van Ooteghem et al. (2009). 


\subsection{Investment analysis}

From the cost and revenue models discussed above, a detailed investment analysis is carried out. All customer classes are considered, and they can choose from the different services offered. Fig. 2 shows the evolution of the cumulative NPV over the lifetime of the project. The combination of a high initial investment and slow user adoption gives a negative NPV in the first years. The payback period is over 6 years. After 10 years, an NPV of almost €3.2 million is obtained.

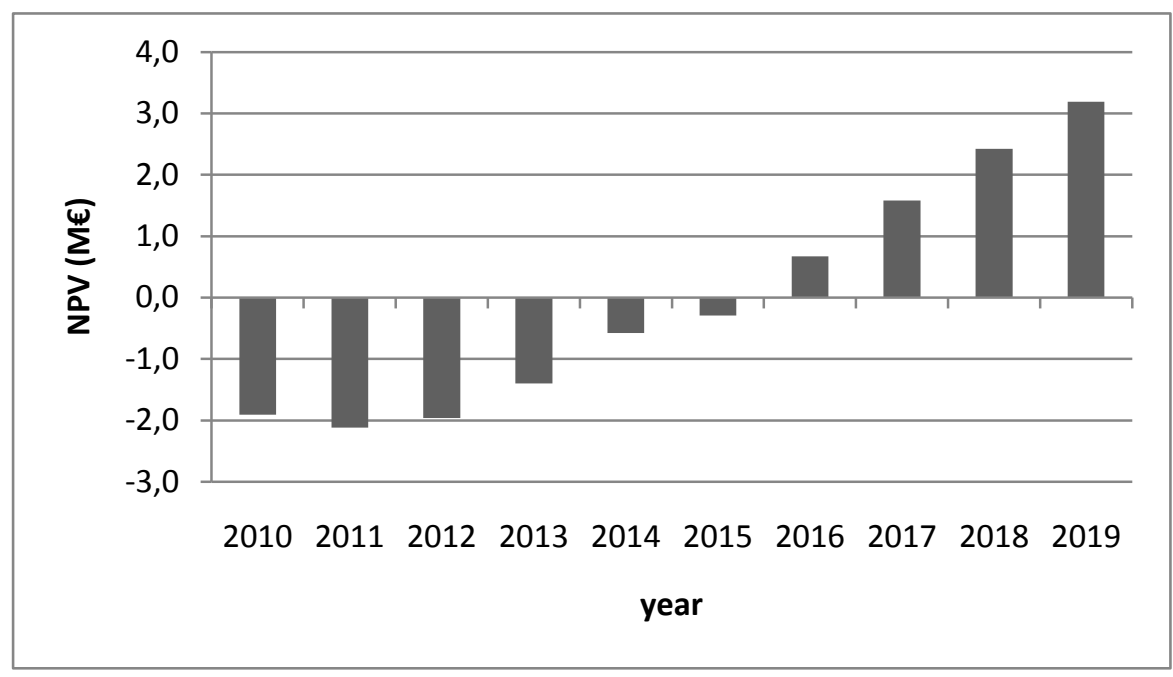

Fig. 2: NPV evolution of WiFi network

\section{Viability of 3G femtocells deployment}

This section evaluates the stand-alone business case for a 3G player, extending its macrocell network to femtocells.

\subsection{Technical info}

3G coverage can be extended by installing femtocells at the customers' house. The technical aspects of both 3G and femtocells are described in the following subsections. 


\subsubsection{G technology}

The third generation of mobile telephony (3G, like UMTS) refers to the transformation of the digital mobile telephony technology (2G, like GSM) to a full mobile Internet access technology. The third generation partnership project (3GPP) tries to provide uniform standardizations for these and other 3G flavors. Release 99 was the original UMTS version. A user typically gets up to 384 kbps downlink for R99 handsets. Other releases (R4 - originally Release 2000, R5, R6, R7, R8 and R9) are already specified to further improve the UMTS technology. The UMTS successor is HSDPA, introduced in Release 5. It improves the downlink data rate for UMTS by using shared channels for different users. As this is an improvement of the 3G UMTS standard technology, it is called a 3.5G technology. 3GPP standards beyond Release 5 further improve the data rate. Release 6 introduces High Speed Uplink Packet Access (HSUPA), new antenna array technologies (beam forming and MIMO) and a new uplink transport channel. It targets 28.8 Mbps downlink and 5.8 Mbps uplink. HSUPA clearly improves the uplink, and is sometimes referred to as 3.75G technology. Release 7 introduces evolved High Speed Packet Access (HSPA) or HSPA+. The target is 42 Mbps downlink and 22 Mbps uplink. Release 8 and 9 introduce Long Term Evolution (LTE) and the Evolved Packet Core (EPC). LTE promises peak rates up to $100 \mathrm{Mbps}$ in downlink and $50 \mathrm{Mbps}$ in uplink.

\subsubsection{Femtocells}

A femtocell is a small cellular base station designed for indoor use. It connects to the service provider's network via the customer's broadband connection instead of connecting via the local mast. So no additional costs for site deployment occur. A femtocell typically supports two to five mobile devices in a residential setting (Tatara Systems, 2009). 
Femtocells are able to provide exceptional cellular service with a typical coverage range of tens of meters. For an MNO, femtocells are attractive, since they can significantly increase the achievable data rates on its mobile network at the customer's property. This is very interesting since delivering high-quality mobile services inside buildings is on one hand a tough challenge for 3G because it uses higher frequency bands where radio signals attenuate more rapidly. On the other hand fast data rates are only possible with a strong signal. Individual connections to the femtocell offload traffic from the macrocellular network, thereby improving network quality for the remaining users (Clausen, 2008).

In this paper, the macrocell 3G (or 3.5G / 3.75G) network of an MNO is extended with femtocells installed by a fixed network operator at the customer side. The fixed network operator then provides access to its customers through both femto- and macrocells (having agreements with the MNO for the latter), and is acting as MVNO. The used release of the 3G technology will depend on the network of the MNO.

\subsection{Techno-economic model}

The used techno-economic model for 3G femtocells is based on the model described in Lannoo et al. (2009) and is briefly introduced in this section. Lannoo et al. (2009) built a first competition model between a WiFi and 3G femtocell operator in the city of Ghent, and this paper extends the previous work with more advanced and realistic competition settings.

\subsubsection{Costs}

\section{Capital expenditures}

For the introduction of 3G femtocells, four scenarios were developed. In each scenario, the MVNO chooses a different subsidization rate of the femtocells. Typically, an 
operator can choose to either charge the customer for the femtocell, or it can buy the femtocell itself, and charge the customer an extra subscription cost. A summary of the different scenarios can be found in Table 5. The operator will need to finance all or a percentage of the femtocell costs, depending on the chosen scenario. After five years, these femtocells are replaced by new ones.

For the deployment of a 3G femtocell network, there are also important network investments required in core equipment. A femtocell gateway needs installation and integration with the existing back office systems. An operator will typically opt for a nationwide rollout of closed access 3G femtocells. To assure comparability with the municipal WiFi rollout, these costs are scaled down to the municipal level. In addition, a replacement investment is included every five years. All costs are based on Lannoo et al. (2009), and prices are again set at the 2010 price level.

Table 5: Different 3G subsidization scenarios

\begin{tabular}{|c|c|c|}
\hline Scenario & Subsidization & Monthly subscription fee \\
\hline $\begin{array}{l}\text { 1) Full subsidization } \\
\text { scenario }\end{array}$ & $100 \%$ & $€ 20$ \\
\hline $\begin{array}{l}\text { 2) } 50 \% \text { subsidization } \\
\text { scenario }\end{array}$ & $50 \%$ & $€ 18$ \\
\hline $\begin{array}{l}\text { 3) No subsidization } \\
\text { scenario }\end{array}$ & $0 \%$ & $€ 16$ \\
\hline 4) Combinatory scenario & Combination & Weighted average \\
\hline
\end{tabular}

\section{Operational expenditures}

Next to the recurring maintenance, a cost for the additional usage of the fixed line connection of the customer is included based on Chandrasekhar, Andrews, and Gatherer (2008). For the maintenance cost of the core equipment, a fractional approach of the total CapEx is used, as done by Clausen, Ho, and Samuel (2008). 
Unlike the WiFi network case, a mobile license is necessary for the 3G network. The cost is influenced by the channel bandwidth, population and the number of BSs. A fixed annual cost per customer per year is included (Lannoo et al., 2009).

To assure comparability with the WiFi case, the same model for the promotion and helpdesk costs is used. The marketing cost is put lower. Since the 3G operator deploys a nationwide network, it can benefit from economies of scale.

\subsubsection{Revenues}

Only direct revenues are considered for the commercial 3G operator. The first three subsidization scenarios are straightforward. Scenario 4 offers flexibility to the customer. In the first years, with high prices for femtocells, customers will opt for leasing the femtocell. For example, in the first year, $80 \%$ of customers will choose for a lease agreement. With femtocell prices dropping fast, customers will become aware of cost benefits when buying their own femtocell. In 2019, it is expected that only $20 \%$ of the customers will choose for leasing the femtocell.

The operator offers closed access femtocells. This opens up possibilities to offer enhanced services, like virtual home numbers or SMS alerts. Not all users will show the same interest in these services. Mostly families with teenagers will be interested in additional services. Therefore, additional revenues for extra services of $€ 5.20$ are only added for families with three or more members (Signal research group, 2009). This comes down to about $40 \%$ of all households in Belgium.

In contrast with the WiFi case, one femtocell per household is needed. The number of adopting inhabitants is divided by the average household size in Ghent, being 2.10. For business users, a distinction between small and medium enterprises (SMEs) and large enterprises is made. For SMEs, which account for $85 \%$ of all businesses, two 
femtocells per business suffice. Large enterprises, with over 100 employees, are covered with $203 \mathrm{G}$ femtocells.

\subsection{Investment analysis}

The investment analysis is carried out the same way as for the WiFi operator. The NPV evolution of all four scenarios can be found in Fig. 3. All scenarios have a positive payoff, with a payback time around two years. This is considerably shorter than the payback period for the WiFi network deployment. The case where the operator subsidizes $100 \%$ is clearly the most profitable, with an NPV of almost $€ 6$ million after 10 years.

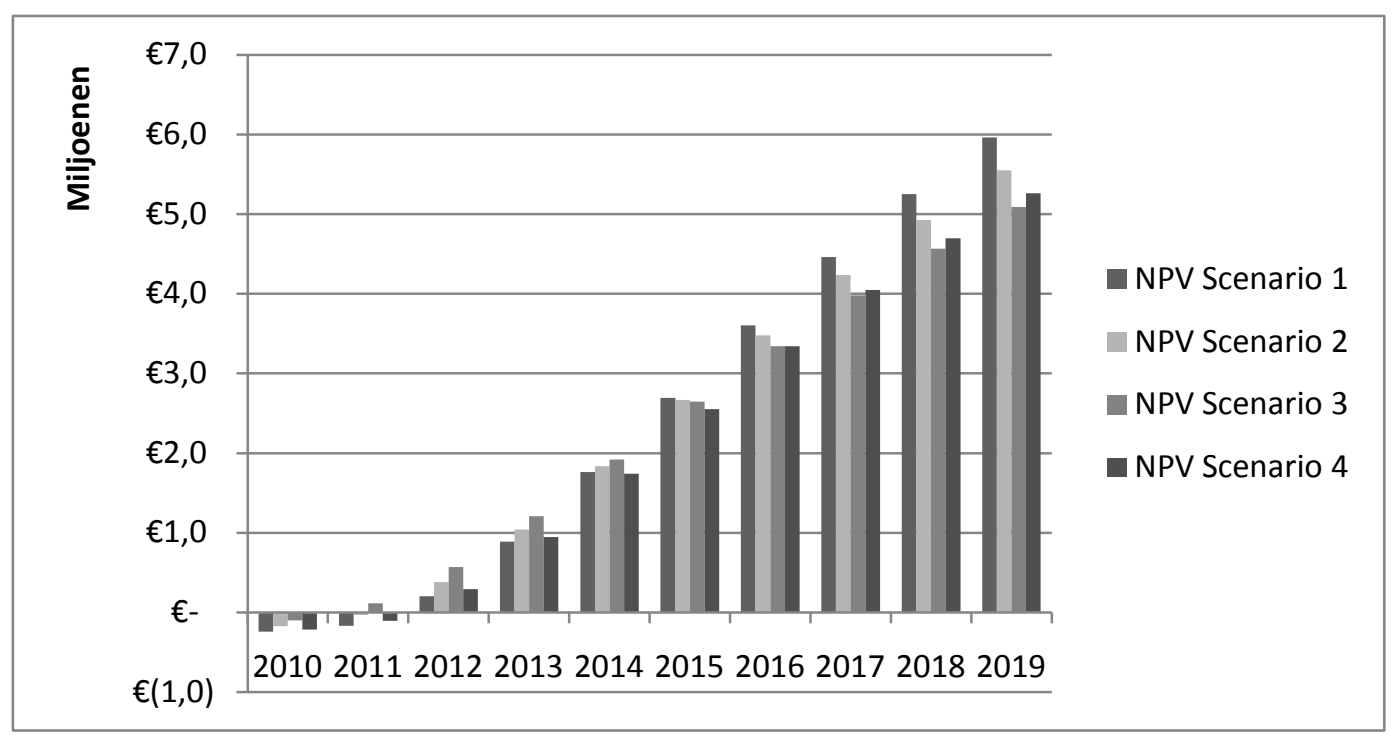

Fig. 3: NPV of different subsidization scenarios for a 3G femtocell network 


\section{Competition modeling}

\subsection{Game theory}

Game theory is "aimed at modeling situations in which decision makers have to make specific actions that have mutual, possibly conflicting, consequences” (Felegyhazi \& Hubaux, 2006, p. 1).

The game between the players described before is investigated. All players play at the same time and have sufficiently good knowledge of each other's possible strategies and payoffs. These assumptions allow representing the game by means of a payoff matrix. This matrix has a payoff (e.g. NPV) for all players for each possible combination of strategies. This is called the strategic form of the game and allows to find an equilibrium in the game. An equilibrium is a set of strategies (one for each player) at which players are not inclined to change their strategy. Different equilibrium concepts have been proposed in the field of game theory. The most commonly known equilibrium is the Nash equilibrium (NE), which is defined as a situation in which no player can gain by unilaterally changing its strategy. In a pure NE, each player will use a pure strategy, whereas in a mixed NE, the players can play mixes (probabilistic combinations) of strategies (Felegyhazi \& Hubaux, 2006). It is often assumed that a game with fully rational players (using this equilibrium as criterion) is expected to result in one of the NEs being chosen.

Typically static games (the game has one stage in which the players interact) can also be reduced or solved by removing strictly dominated strategies. These dominated strategies have a strictly lower payoff than another (dominant) strategy for all possible counterstrategies. No fully rational player would play a strictly dominated strategy but would instead play the dominant strategy. As such this strategy can be removed for the considered player. By iteratively using this approach for the different players, the 
matrix of the game can be simplified and can in some case be solved to a unique strategic choice for each player. In these cases, this strictly dominant strategy set is the only NE of the game.

\subsection{Strategies}

Since the different players operate in the same geographical market, the total market potential can be modeled by the adoption curve presented in Section 2.1. Lannoo et al. (2009) provides a detailed overview of the division of the market between the different players.

The main strategy to attract customers studied in this paper is price change. The WiFi player has price schemes based on the offered service. Its strategy will therefore be changing its premium subscription price, either up or down. The other services are also offered, and their price scales up or down based on the change of the high bandwidth service price. For the $3 G$ femtocell player, an extra strategic option emerges. Next to changing its premium subscription price, this player can choose between different subsidization rates. In Lannoo et al. (2009) the price setting strategy was chosen. This work is now complemented with the subsidization strategic choice. Both WiFi players are offered an extra strategic choice, namely cooperation via a PPP. Under this strategy, the four WiFi services are offered by the PPP. Costs and revenues are adequately shared between both players. Since the municipality does not have profit, but public welfare as its main driver, the non-profit behavior was added to the business case via the indirect revenues concept. 


\section{Competition or partnership between WiFi operators?}

Since a municipality acts in the best interest for its inhabitants, the strategic decision variable for the municipality in this game will be the maximization of the sum of its payoff and the discounted indirect revenues.

Some additional potential problems need to be tackled before modeling this game. State aid is not allowed, so the municipality must invest according to the market economy investor principle. Similar to the Amsterdam case, mentioned in section 2.4, the municipality in this model invests $30 \%$ of the necessary funds, and reaps $30 \%$ of the benefits, if any.

The municipality can also choose to rollout an independent network. In this situation, its strategies concur with the price strategies of the commercial WiFi player. Table 6 summarizes the different strategies for each player.

Table 6: Strategic choices for each player

\begin{tabular}{|l|l|l|l|}
\hline \multicolumn{2}{|c|}{ Player } & \multicolumn{1}{c|}{ Strategy } & \multicolumn{1}{c|}{ Strategic choices } \\
\hline 1 & Commercial WiFi & Price strategy & $€ 18-€ 21$ \\
\hline 2 & Municipal WiFi & $\begin{array}{l}\text { Partnership \& price } \\
\text { strategy }\end{array}$ & $\begin{array}{l}\text { Independent vs. PPP } \\
€ 18-€ 21\end{array}$ \\
\hline 3 & 3 G player & Price strategy & $\begin{array}{l}\text { Subsidization } \\
\text { percentage }\end{array}$ \\
\hline
\end{tabular}

These strategies result in an asymmetric matrix. Player 1 and 3 both have four different options, while Player 2 has five. The resulting payoff matrix can be found in Table 7. It can be concluded that the municipality will choose for a PPP with the commercial player. This strategy is strictly dominant for the independent strategic choice. Using strict dominance, the NE $(0.05 ; 1.56 ; 1.10)$ can be derived. It is indicated in negative in Table 7. The municipality should always choose to partner with a commercial player. 
The impact of other adoption choices on the NE was also checked. Both a lower and a higher adoption resulted in the same equilibrium being chosen, even with adoption curves not only differing by a multiplicative factor. Therefore it can be concluded that the results are not impacted by the adoption choices made.

When the NE is analyzed for the other players, it is clear that it is also in the best interest for the commercial WiFi player to engage in this PPP. Direct competition with the municipality would result in a negative business case, while the PPP offers a slightly positive payoff for the commercial player. Due to this minimal result, the reasons for the commercial player to engage in this PPP could be questioned. Non profit related incentives for the commercial player would be brand image, customer satisfaction or reduced churn. The municipality could also offer extra advantages to the private player, like free site access or backhaul, so both players benefit from the partnership.

The 3G player will, in contradiction with the results of the static business case analysis from Section 4.3, not choose for the full subsidization scenario. When this player lowers its monthly subscription prices, it gains extra market share that compensates the lower profit margins. It is clear that a game theoretic analysis offers more detailed insight in the price setting game played by all players. A naive player would choose to fully subsidize the 3G femtocells, while it is clear that this strategy does not result in the highest payoff.

A price war behavior was also noticed in the game theoretic analysis. The equilibrium consists of the lowest price for the premium service. The WiFi players have an intention to keep lowering their prices, to capture extra market share. Continuously lowering prices would result in negative profit margins, which is forbidden by national and European legislation. Too low prices compared with other, mainly fixed services, 
offered by the commercial player, could result in an increase churn from fixed towards mobile access, shifting part of the resources to the mobile market. 
Table 7: Strategic form for partnership scenario, dominant strategies in negative (NPV in M€, lifetime of 10 years)

\begin{tabular}{|c|c|c|c|c|c|c|c|c|c|c|c|c|c|c|c|c|}
\hline & & \multicolumn{15}{|c|}{ 2. Municipality } \\
\hline & & \multicolumn{3}{|c|}{ enabler } & \multicolumn{3}{|c|}{ independent } & \multicolumn{3}{|c|}{ independent } & \multicolumn{3}{|c|}{ independent } & \multicolumn{3}{|c|}{ independent } \\
\hline 1. Commercial Wifi & 3. $3 \mathrm{G}$ & & & & & 18 & & & 19 & & & 20 & & & 21 & \\
\hline \multirow{4}{*}{18} & Scenario 1 & 0.33 & 1.81 & 0.52 & -1.75 & 0.23 & -0.17 & -1.73 & 0.12 & -0.10 & -1.67 & -0.04 & 0.07 & -1.61 & -0.26 & 0.23 \\
\hline & Scenario 2 & 0.18 & 1.68 & 0.87 & -2.19 & -0.15 & 0.40 & -2.14 & -0.26 & 0.43 & -2.06 & -0.44 & 0.55 & -2.00 & -0.70 & 0.69 \\
\hline & Scenario 3 & 0.05 & 1.56 & 1.10 & -2.57 & -0.51 & 0.80 & -2.52 & -0.62 & 0.85 & -2.43 & -0.82 & 0.96 & -2.35 & -1.10 & 1.05 \\
\hline & Scenario 4 & 0.21 & 1.70 & 0.74 & -2.16 & -0.10 & 0.26 & -2.10 & -0.21 & 0.30 & -2.02 & -0.40 & 0.41 & -1.95 & -0.64 & 0.52 \\
\hline \multirow{4}{*}{19} & Scenario 1 & 0.26 & 1.71 & 0.57 & -1.77 & 0.36 & -0.10 & -1.74 & 0.26 & -0.04 & -1.67 & 0.08 & 0.13 & -1.60 & -0.13 & 0.29 \\
\hline & Scenario 2 & 0.12 & 1.59 & 0.91 & -2.19 & 0.00 & 0.43 & -2.14 & -0.12 & 0.48 & -2.06 & -0.29 & 0.60 & -1.98 & -0.55 & 0.73 \\
\hline & Scenario 3 & 0.00 & 1.48 & 1.13 & -2.61 & -0.35 & 0.84 & -2.54 & -0.44 & 0.89 & -2.44 & -0.67 & 1.00 & -2.36 & -0.92 & 1.07 \\
\hline & Scenario 4 & 0.16 & 1.62 & 0.78 & -2.13 & 0.03 & 0.30 & -2.07 & -0.07 & 0.34 & -2.00 & -0.24 & 0.46 & -1.92 & -0.49 & 0.57 \\
\hline \multirow{4}{*}{20} & Scenario 1 & 0.20 & 1.64 & 0.76 & -1.83 & 0.58 & 0.07 & -1.78 & 0.47 & 0.14 & -1.69 & 0.30 & 0.30 & -1.62 & 0.10 & 0.45 \\
\hline & Scenario 2 & 0.07 & 1.53 & 1.08 & -2.28 & 0.22 & 0.57 & -2.25 & 0.10 & 0.62 & -2.15 & -0.06 & 0.75 & -2.06 & -0.30 & 0.86 \\
\hline & Scenario 3 & -0.05 & 1.42 & 1.27 & -2.67 & -0.12 & 0.98 & -2.63 & -0.22 & 1.02 & -2.53 & -0.44 & 1.08 & -2.44 & -0.68 & 1.17 \\
\hline & Scenario 4 & 0.11 & 1.57 & 0.93 & -2.22 & 0.25 & 0.42 & -2.18 & 0.15 & 0.47 & -2.08 & -0.02 & 0.58 & -1.99 & -0.26 & 0.71 \\
\hline \multirow{4}{*}{21} & Scenario 1 & 0.13 & 1.57 & 0.93 & -1.94 & 0.79 & 0.25 & -1.90 & 0.70 & 0.31 & -1.80 & 0.53 & 0.47 & -1.73 & 0.35 & 0.55 \\
\hline & Scenario 2 & 0.00 & 1.45 & 1.21 & -2.40 & 0.44 & 0.72 & -2.33 & 0.34 & 0.77 & -2.22 & 0.16 & 0.88 & -2.15 & -0.07 & 1.01 \\
\hline & Scenario 3 & -0.12 & 1.34 & 1.40 & -2.82 & 0.13 & 1.07 & -2.77 & 0.00 & 1.11 & -2.65 & -0.19 & 1.20 & -2.53 & -0.43 & 1.29 \\
\hline & Scenario 4 & 0.04 & 1.49 & 1.05 & -2.32 & 0.48 & 0.55 & -2.28 & 0.39 & 0.60 & -2.18 & 0.22 & 0.73 & -2.08 & -0.01 & 0.84 \\
\hline
\end{tabular}




\section{Viability of the PPP under extra 3G competition}

In the previous paragraph, a PPP between a municipal and a commercial WiFi operator was found to be the dominant strategic choice. However, the low result for the commercial WiFi player is a reason for concern. In a realistic setting, typically more than one provider has the ability to offer 3G access. In Belgium, three players obtained a 3G license, and two of them can effectively offer full 3G coverage to their customers. In this section, the impact of extra 3G MVNOs entering the market will be researched. Extra players competing in the same market will reduce the customer base of the PPP, and thereby further reduce its payoff. This could jeopardize the PPP altogether, as in the case of a negative payoff, the commercial partner has no intention to participate. In this strategic game, the PPP is played out against two 3G players, in order to model a more realistic scenario. Only the payoff of the commercial partner is presented in the strategic form, to improve readability of the matrix. The PPP can choose between the four different premium service price settings. The strategies for the two 3G players are the different subsidization scenarios. They are listed in Table 8. The resulting strategic form can be found in Table 9 .

The NE found for this game $(-0.82 ; 0.67 ; 0.67)$ again shows the 3G MVNOs opting for the no subsidization scenario. It is clear that in a competitive environment, the lower subsidization costs weigh up against the lower subscription revenues.

Notice the negative payoff for the commercial WiFi player. Participating in a WiFi network rollout proofs to be unprofitable under these conditions. The game theoretic results fit with the observation that only few municipal wide WiFi networks are rolled out. However, it should be noted that the total payoff for the PPP under these circumstances remains positive. Again, changing the initial adoption assumptions did not influence the resulting NE. 
Table 8: Strategic choices for the different players in the realistic game

\begin{tabular}{|l|l|l|l|}
\hline \multicolumn{2}{|c|}{ Player } & \multicolumn{1}{|c|}{ Strategy } & \multicolumn{1}{c|}{ Strategic choices } \\
\hline 1 & PPP WiFi & Price strategy & $€ 18-€ 21$ \\
\hline 2 & 3 G player 1 & Price strategy & $\begin{array}{l}\text { Subsidization } \\
\text { percentage }\end{array}$ \\
\hline 3 & 3G player 2 & Price strategy & $\begin{array}{l}\text { Subsidization } \\
\text { percentage }\end{array}$ \\
\hline
\end{tabular}


Table 9: Strategic form for the realistic scenario, dominant strategy in negative (NPV in M€, lifetime of 10 years)

\begin{tabular}{|c|c|c|c|c|c|c|c|c|c|c|c|c|c|}
\hline \multirow[b]{2}{*}{ 1. Commercial Wifi } & \multirow[b]{2}{*}{ 3. $3 \mathrm{G}$} & \multicolumn{12}{|c|}{ 2. $3 \mathrm{G}$} \\
\hline & & \multicolumn{3}{|c|}{ Scenario 1} & \multicolumn{3}{|c|}{ Scenario 2} & \multicolumn{3}{|c|}{ Scenario 3} & \multicolumn{3}{|c|}{ Scenario 4} \\
\hline \multirow{4}{*}{18} & Scenario 1 & 0.03 & 0.49 & 0.49 & -0.16 & 0.78 & 0.23 & -0.32 & 1.04 & -0.03 & -0.09 & 0.65 & 0.28 \\
\hline & Scenario 2 & -0.16 & 0.23 & 0.78 & -0.40 & 0.57 & 0.57 & -0.60 & 0.87 & 0.38 & -0.36 & 0.45 & 0.61 \\
\hline & Scenario 3 & -0.32 & 0.03 & 1.04 & -0.60 & 0.38 & 0.87 & -0.82 & 0.67 & 0.67 & -0.54 & 0.26 & 0.91 \\
\hline & Scenario 4 & -0.09 & 0.28 & 0.65 & -0.36 & 0.61 & 0.45 & -0.54 & 0.91 & 0.26 & -0.30 & 0.47 & 0.47 \\
\hline \multirow{4}{*}{19} & Scenario 1 & -0.14 & 0.47 & 0.47 & -0.35 & 0.78 & 0.26 & -0.49 & 1.03 & 0.01 & -0.28 & 0.66 & 0.30 \\
\hline & Scenario 2 & -0.35 & 0.26 & 0.78 & -0.58 & 0.57 & 0.57 & -0.73 & 0.87 & 0.38 & -0.52 & 0.44 & 0.62 \\
\hline & Scenario 3 & -0.49 & 0.01 & 1.03 & -0.73 & 0.38 & 0.87 & -0.95 & 0.67 & 0.67 & -0.68 & 0.27 & 0.91 \\
\hline & Scenario 4 & -0.28 & 0.30 & 0.66 & -0.52 & 0.62 & 0.44 & -0.68 & 0.91 & 0.27 & -0.47 & 0.48 & 0.48 \\
\hline \multirow{4}{*}{20} & Scenario 1 & -0.38 & 0.52 & 0.52 & -0.55 & 0.85 & 0.36 & -0.69 & 1.07 & 0.12 & -0.49 & 0.72 & 0.40 \\
\hline & Scenario 2 & -0.55 & 0.36 & 0.85 & -0.78 & 0.65 & 0.65 & -0.94 & 0.94 & 0.46 & -0.73 & 0.52 & 0.70 \\
\hline & Scenario 3 & -0.69 & 0.12 & 1.07 & -0.94 & 0.46 & 0.94 & -1.17 & 0.75 & 0.75 & -0.87 & 0.34 & 0.97 \\
\hline & Scenario 4 & -0.49 & 0.40 & 0.72 & -0.73 & 0.70 & 0.52 & -0.87 & 0.97 & 0.34 & -0.66 & 0.56 & 0.56 \\
\hline \multirow{4}{*}{21} & Scenario 1 & -0.65 & 0.59 & 0.59 & -0.81 & 0.92 & 0.45 & -0.94 & 1.12 & 0.23 & -0.76 & 0.79 & 0.50 \\
\hline & Scenario 2 & -0.81 & 0.45 & 0.92 & -1.01 & 0.73 & 0.73 & -1.20 & 0.97 & 0.54 & -0.97 & 0.59 & 0.76 \\
\hline & Scenario 3 & -0.94 & 0.23 & 1.12 & -1.20 & 0.54 & 0.97 & -1.42 & 0.82 & 0.82 & -1.13 & 0.42 & 1.00 \\
\hline & Scenario 4 & -0.76 & 0.50 & 0.79 & -0.97 & 0.76 & 0.59 & -1.13 & 1.00 & 0.42 & -0.91 & 0.63 & 0.63 \\
\hline
\end{tabular}




\section{Conclusion}

A lot of attention is going to city-wide wireless access networks, since they promise to bring ubiquitous broadband access together with a broad range of advantages, like a stimulus for economic growth and extra employment. However, the rollout of these networks is only taking off slowly. By investigating the prevailing cooperation and competition models between WiFi and 3G players in a realistic competitive environment, this paper shows how the application of game theory on a realistic case fits these observations.

Two important questions concerning this topic are answered in this paper. First, the strategic behavior of a public authority and commercial operators when they choose to invest in a wireless next generation access network (NGAN) is researched. Detailed numerical business models for the different players were developed, which all showed to be profitable when a standard economic investment analysis was performed. However, this analysis cannot capture the impact of competition on the different business cases. Using a game theoretic approach to model this competitive environment, the cooperation and competition between the different players was studied. The model clearly showed that when the WiFi players roll out the network simultaneously and independently in this environment, their business cases are not profitable. Using the Nash equilibrium concept from game theory, it was proven that a public private partnership (PPP) is the only possible cooperation model for public and commercial WiFi players to roll out a city-wide wireless access network. An additional result from this analysis is the different strategy chosen by the $3 G$ mobile virtual network operator (MVNO). The best scenario found in the static analysis proofs to be the least interesting choice in the competitive setting. While the static analysis suggest to choose for the highest monthly subscription price, the game theoretic analysis shows 
that the higher market share gained by a lower subscription price offsets the lower revenues per customer. It is clear that game theory offers valuable insight to decision makers for investment analysis compared to the static NPV analysis.

The second question focuses on the strategic behavior of the different players when extra competition enters the market. While a PPP was shown to be the only prevailing strategy for the WiFi operators, the market reaction when extra $3 \mathrm{G}$ players enter the market were investigated. The extra competition poses problems for the WiFi partnership, since its market share is reduced. Building further on the game theoretic model, a new strategic game was developed with extra 3G players competing for the market share with the PPP. Although the payoff in equilibrium state for the entire PPP remained positive, it was shown that the return for the commercial player in the PPP becomes negative, thereby completely removing its incentive to participate in the partnership. No intention to either rollout an independent or a joined WiFi network remains. These findings fit the overall observation that the rollout of municipal wireless networks remains slow.

As subsidization is not allowed, the municipality must find other ways to convince the commercial player to step into the PPP. Topics of future work should focus on these options for the municipality. Providing cheap backhauling and cheap access to public sites are only a few possibilities. Note that an improved WiFi technology also will reduce the number of antennas needed, which will also have positive effects on the final business case. The trend for the lowest price setting in the game theoretic approach was also mentioned. This could result in a price war behavior. Does this trend persist, or is there a point where the increased market share does not weigh up to the lowering return per user? In addition, the price competition could also be extended with a more service based competition. 
Acknowledgement

This work was partially carried out in the framework of the COST ISO605 Econ@Tel action.

\author{
References
}

Altman, E., Boulogne, T., El-Azouzi, R., Jiménez, T., \& Wynter, L. (2006). A survey on networking games in telecommunications. Computers \& Operations Research, 33(2), 286-311.

Cardenas, A., Garcia-Molina, M., Sales, S., \& Capmany, J. (2004). A new model of bandwidth growth estimation based on the gompertz curve: Application to optical access networks. Journal of Lightwave Technology, 22(11), 2460-2468.

Casier, K., Lannoo, B., Van Ooteghem, J., Verbrugge, S., Colle, D., Pickavet, M., \& Demeester, P., (2009). Game-theoretic optimization of a FTTH municipality network rollout. Journal of Optical Communications and Networking, 1(1), 30-42.

Chandrasekhar, V., Andrews, J. G., \& Gatherer, A. (2008). Femtocell networks: A survey. IEEE Communications Magazine, 46(9), 59-67.

Clausen, H. (2008). Co-channel operation of macro- and femtocells in hierarchical cell structure. International Journal of Wireless Information Networks, 15(3-4), 137-147.

Clausen, H., Ho, L., \& Samuel, L. G. (2008). An overview of the femtocell concept. Bell Labs Technical Journal, 13(1), 221.

De Marez, L., Evens, T., \& Stragier, J. (2011) Diffusion theory vs. today's ICT environment. Unpublished manuscript, Ghent University, Ghent, Belgium.

Felegyhazi, M., \& Hubaux, J. P. (2006). Game theory in wireless networks: A tutorial. EPFL Techical Report.LCA-REPORT 2006-002. Retrieved from http://ns2.virusflags.dc.hu/ mfelegyhazi/publications/FelegyhaziH06tutorial.pdf

ITU (2009). ITU Mobile telephony statistics. Retrieved from http://www.itu.int/ITU-D/ict/statistics/

Lannoo, B., Tahon, M., Van Ooteghem, J., Pareit, D., Casier, K., Verbrugge, S., Moerman, I., Pickavet, M., \& Demeester, P. (2009). Game-theoretic evaluation of competing wireless access networks for offering Mobile Internet. Paper presented at the CRNI 2009, 20 November 2009, Brussels, Belgium.

Lannoo, B., Verbrugge, S., Van Ooteghem, J., Quinart, B., Colle, D., Pickavet, M., Demeester, P. (2007). Business scenarios for a WiMAX deployment in Belgium. Proceedings of the IEEE Mobile WiMAX Symposium, 27-28 March 2007. Orlando, Florida, USA.

Point Topic (2010). World broadband statistics. Retrieved from http://point-topic.com

RAPID (2006). State aid: Commission concludes City of Amsterdam investment in fibre network is not state aid: Press release. Retrieved from http://europa.eu/rapid/pressReleasesAction.do?reference=IP/07/1889

Sadowski, B., Verheijen, M., \& Nucciarelli, A. (2008). From experimentation to citywide rollout: Real options for a municipal WiMax network in the Netherlands. Communications and Strategies, 70. 101-123.

Sharpe, W. F. (1963). A simplified model for portfolio analysis. Management Science, 9(2), 277-293.

Signal research group (2009). Femtocell forum Femtocell Business case. Retrieved from http:/www.3gamericas.org/documents/Femto\%20Forum\%20Business\%20Case\%20Whitepaper \%20Signals\%20Research\%20Apr09.pdf

Smura, T. (2006). Competitive potential of WiMax in the broadband access market: A techno-economic analysis. Proceedings of the 16th European Regional ITS Conference, 4-6 September 2005. Porto, Portugal

Tatara Systems (2009). Femtocell architectures. Retrieved from http://www.tatarasystems.com/contentmgr/showdetails.php/id/467

Vacature (2010). Salariskompas. Retrieved from http://salariskompas.vacature.com/

Van Ooteghem, J., Lannoo, B., Casier, K., Verbrugge, S., Tanghe, E., Joseph, W., Colle, D., Martens, L., Pickavet, M., \& Demeester, P. (2009). Municipalities as a driver for wireless broadband access. Wireless Personal Communications, 49(3), 391-414.

Verbrugge, S., Casier, K., Van Ooteghem, J., \& Lannoo, B. (2009). Practical steps in techno-economic evaluation of network deployment planning. Paper presented at the Globecom 2009. 30 November - 4 December 2009, Honolulu, Hawaii, USA.

ZapFi (2010). ZapFi: Bruges - Why city-wide WIFI networks make sense (and business). Paper presented at the CTTE 2010.7-9 June 2010, Ghent, Belgium. 